\title{
HINOKITIOL-AMELIORATED DIETHYLNITROSAMINE-INDUCED HEPATOCARCINOGENESIS THROUGH ANTIOXIDANT MECHANISM IN RATS: IN VITRO AND IN VIVO STUDY
}

\author{
MOHAMED ZEREIN FATHIMA ${ }^{1}$, MOHAMED NAINAR ${ }^{2}$, SOMASUNDARAM ${ }^{1}{ }^{1}$, SHANMUGARAJAN TS ${ }^{1 *}$ \\ ${ }^{1}$ Department of Pharmaceutics, School of Pharmaceutical Sciences, Vels University (VISTAS), Chennai - 600 117, Tamil Nadu, \\ India. ${ }^{2}$ Chettinad Acedemy of Research and Education, Chettinad Health City, Kanchipuram - 603 103, Tamil Nadu, India. \\ Email: shanmuga5@yahoo.com
}

Received: 12 August 2017, Revised and Accepted: 07 March 2018

ABSTRACT

Objective: Chemoprevention seems to be the best strategy for lowering the incidence of liver cancer. Therefore, this study has been initiated to investigate the hinokitiol (HIOL) supplementation which could prevent oxidative stress induced by hepatocarcinogen, diethylnitrosamine (DEN) in rats.

Methods: The biochemical parameters such as tissue damaging enzymes, namely, alanine transaminase (ALT), alkaline phosphatase (ALP), aspartate aminotransferase (AST), and attack-free period and enzymatic antioxidants, namely, glutathione (GSH), catalase (CAT), glutathione peroxidase (GPx), glutathione-S-transferase (GST), glutathione reductase (GR), superoxide dismutase (SOD), and histopathological changes were estimated.

Results: DEN-treated rats shows increased ALT, ALP, and AST and decreased GSH, GST, CAT, GPx, GR, and SOD activities in liver tissues. The DENtreated group ( $200 \mathrm{mg} / \mathrm{kg}$ body weight single intraperitoneal injection) with phenobarbital $0.05 \%$ orally showed the severe histopathological lesions in liver tissue. Whereas, the groups received HIOL along with DEN shown a comparatively lesser damage. Here, the HIOL supplementation ameliorated the biochemical parameters as well as evoked enzymatic antioxidants in DEN-induced rats to the control values.

Conclusion: The HIOL possesses potent antioxidant property, in this credence to that conception, the treatment with HIOL may prevent the development of chemical-induced hepatocarcinogenesis in rats by free radical scavenging mechanism.

Keywords: Hinokitiol, Diethylnitrosamine, Antioxidant activity, Hepatocarcinogenesis, Enzymes.

(C) 2018 The Authors. Published by Innovare Academic Sciences Pvt Ltd. This is an open access article under the CC BY license (http://creativecommons. org/licenses/by/4. 0/) DOI: http://dx.doi.org/10.22159/ajpcr.2018.v11i6.21950

\section{INTRODUCTION}

Carcinogenesis is a heterogeneous step involving mutation and clonal enlargement of the mutated cell. Chemical as well as physical agents induce reactive oxygen species (ROS) and can modulate this heterogeneous process. The cancer induced by carcinogens via producing the ROS and free radicals also been identified. Oxidative stress (OS) is a known mediator of cancer. OS is an imbalance between the production of ROS and response from the antioxidant defense systems or reactive intermediates such as free radicals and peroxides [1]. It has been well documented that the free radicals or ROS is balanced by the enzymatic and non-enzymatic antioxidants. Antioxidant defense mechanism is ultimately important to the removal of free radical (pro-oxidants) and provides the maximum protection from carcinogenesis. Our previous studies reported that imbalance in redox state by antioxidant enzymes includes catalase (CAT), superoxide dismutase (SOD), glutathione reductase (GR), glutathione peroxidase (GPx), and glutathione (GSH) in stress-induced paradigms [2].

The formation of toxic reactive intermediates due to perturbations in redox balance may damage the DNA. Mutational events of initiation and progression is due to oxidative damage [3]. It has been well documented that ROS-dependent signaling mechanisms control the gene expression which are contributing in tumor promotion. ROS can induce the signal transduction pathway which leads to activation of transcription factors (e.g. Nrf2 and nuclear factor- $\kappa \mathrm{B}[\mathrm{NF}-\kappa \mathrm{B}]$ ). The altered gene expressions elicited by ROS contribute to the carcinogenesis process [4].

Diethylnitrosamine (DEN) is a well-known carcinogen for inducing cancer in the liver. Generating the more oxygen free radicals may cause oxidative damage to the biomolecules which results in carcinogenesis.
$\mathrm{N}$-Nitrosodiethylamine displayed as important environmental carcinogen in $\mathrm{N}$-Nitrosamine classification, and it induces the liver cancer by damaging the DNA of hepatocytes [5]. Hence, the nitrosoamines influence the role on the OS in both metabolism and the carcinogenic actions. Antioxidant compounds show the strong defense mechanism against the damaged cells caused by free radical-induced OS. Reports revealed that the DEN was bioactivated by cytochrome P450 enzyme CYP2E1 in the liver which results in DNA-adduct formation through alkylation thereby provoke the carcinogenesis [6].

The redox state is an essential factor for the tumor growth by initiating the induction of signaling pathways affecting the cell cycle progression, proliferation, cell survival, apoptosis and metastasis. The antioxidant compounds hamper the levels of ROS and modulate the signaling mechanisms thereby providing the potential effect against cancer. Therefore, administration of antioxidants may ameliorate the DEN-induced hepatocarcinogenesis in rats [7].

Hinokitiol (HIOL), also known as beta-thujaplicin, is a tropolone derivative found in the heartwood of cupressaceous plants. It is an iron-chelating compound triggering apoptosis through the activation of caspase- 3 and displays the various biological activities including anti-inflammatory, antibacterial, antifungal, and antitumor activity. HIOL has potential to inhibit the inflammatory reaction through its antioxidant potential in human corneal epithelial (HCE) cells against $\mathrm{H}_{2} \mathrm{O}_{2}$ by modulating antioxidant enzymes SOD, CAT, total antioxidant capacity, and anti-apoptotic pathway by Bcl-2 downregulation and Bax upregulation [8]. The previous reports state that the HIOL possesses anti-inflammatory activity in HCE cells which inhibits the NF- $\kappa \mathrm{B}$ and downregulates the pro-inflammatory mediators [9]. 
HIOL inhibits metastasis, mitogen-activated protein kinase (MAPK), matrix metalloproteinase- 1 , and transcription factors c-Jun and NF-KB in B16-F10 cells. Recent studies reported that the HIOL inhibited the DNA damage, cell cycle arrest, senescence, and autophagy in lung adenocarcinoma cells [10]. Therefore, it is important to evaluate the cytotoxicity potential of HIOL in HepG2 cell lines and further to evaluate the antioxidant potential of HIOL against OS provoked by DEN-induced hepatic perturbations.

\section{METHODS}

Chemicals

DEN and HIOL were purchased from Sigma Aldrich, Bengaluru. The rest of the chemicals used in the protocol was of analytical grade.

\section{Animals}

A total of 36 Wistar strain male albino rats weighing about 150-180 g were used, which are divided into 6 groups. Each contains 6 animals purchased from Tamil Nadu Veterinary and Animal Sciences University (Tanuvas), Madhavaram, Chennai, India. The animals were housed in cages under proper environmental conditions and fed with proper diet and free access to water. The protocol used for this study was approved by the Institutional Animal Ethics Committee (IAEC) as per instructions from the Purpose of Control and Supervision of Experiments on animals (CPCSEA).

\section{CPCSEA approval no - 290/Po/Re/S/2000/CPCSEA}

\section{IAEC No - XVII/VELS/PCOL/04/2000/CPCSEA/IAEC/06.10.15}

\section{Experimental design}

The rats weighing around 150-200 g were segregated into six groups with 6 rats in each cage. The present study was designed for 16 weeks. Group-I assigned as normal control treated with normal saline. GroupII received a single intraperitoneal injection of DEN $(200 \mathrm{mg} / \mathrm{kg})$. After a brief recovery period of 1 week, the rats were given PB $(0.05 \%$ in drinking water). The administration of phenobarbital was continued for another 15 weeks. Group-III received HIOL alone with $75 \mu \mathrm{g} / \mathrm{kg}$ body weight (bw) through oral administration for 16 weeks without DEN and phenobarbital administration. Group IV received simultaneously with DEN and HIOL ( $200 \mathrm{mg} / \mathrm{kg}$ and $25 \mu \mathrm{g} / \mathrm{kg} / \mathrm{bw})$, and the oral administration was then continued throughout the experimental period along with the administration of phenobarbital for 15 weeks. Group $\mathrm{V}$ received simultaneously with DEN and HIOL (200 mg/kg and $50 \mu \mathrm{g} / \mathrm{kg} / \mathrm{bw}$ ), and the oral administration was then continued throughout the experimental period along with the administration of phenobarbital for 15 weeks. Group VI received simultaneously with DEN and HIOL $(200 \mathrm{mg} / \mathrm{kg}$ and $75 \mu \mathrm{g} / \mathrm{kg} / \mathrm{bw}$ ), and the oral administration was then continued throughout the experimental period along with the administration of phenobarbital for 15 weeks.

\section{Estimation of biochemical parameters}

Serum was separated from blood by collecting the blood under anesthesia from the retro-orbital plexus with no anticoagulant. Serum glutamate pyruvate transaminase, serum glutamic-oxalocetic transaminase, and alkaline phosphatase (ALP) were estimated by the method developed by King and Premalatha et al. [11-14].

\section{Antioxidants and OS biomarkers}

An lipid peroxidation (LPO) level in the liver was measured by the method of Ohkawa et al. [15]. The absorbance was measured at $532 \mathrm{~nm}$ and the concentration was expressed as nmol malondialdehyde (MDA) min/ $\mathrm{mg} /$ protein. SOD was assayed by the described method developed by Misra and Fridovich [16]. CAT activity was measured as described by Sinha [17]. GPX activity was estimated using the method developed by Ahrens [18] based on the reaction between GSH remaining after the action of GPx an 5,5' dithio-bis-(2-nitro benzoic acid) to form complex that absorbs maximum at $412 \mathrm{~nm}$ [19]. The GSH level was measured by the method described by Ellman [20]. GR activity was assayed according to the method described previously by Staal et al. [21-24].

\section{Histopathological examination}

At the end of the experimental period, all rats were sacrificed under anesthesia. The liver tissues were immediately removed and preserved in the natural phosphate-buffered saline (10\%). The $5 \mu \mathrm{m}$ samples of liver tissue were cut, hydrated, deparaffinized, and stained with eosin and hematoxylin. The prepared slides were further used for the examination of various changes occur in the liver and compared with the other groups.

\section{Statistical analysis}

The results were expressed as mean \pm standard deviation (SD). Oneway ANOVA was used for the statistical significance between more than two groups though using the least significance difference test. When the $p$ value was $p<0.05, p<0.01$, and $p<0.001$, the results were termed as statistically significant.

Cytotoxicity - 3-(4, 5-dimethylthiazolyl-2)-2, 5-diphenyltetrazolium bromide (MTT) assay on HepG2 cells

The effect of HIOL on HepG2 cell lines was evaluated using a WST-1 cell proliferation kit (Roche Applied Science, Mannheim, Germany). HepG2 cells were routinely cultured as monolayers in Roswell Park Memorial Institute medium supplemented with $20 \%$ fetal bovine serum. Cells were seeded in 96-well culture plates and allowed to adhere to the plate surface for $36 \mathrm{~h}$ before being exposed to various concentrations from 0 to $10 \mu \mathrm{g} / \mathrm{mL}$ of HIOL for $24 \mathrm{~h}$. The HIOL was diluted in complete media to reach the final concentrations, and the final concentration was used as control. The yellow tetrazolium MTT reagent was then added to each well and incubated for $40 \mathrm{~min}$ in a humidified atmosphere $\left(37^{\circ} \mathrm{C}, 5 \% \mathrm{CO}_{2}\right)$. Formazan dye produced by metabolically active cells was measured at $450 \mathrm{~nm}$ by microplate ELISA reader. The results were obtained from the average of three independent experiments, and data were expressed as mean cell growth (\%) \pm SD. Statistical comparison of the results was carried out using one-way analysis of variance (ANOVA) test. The cytotoxicity of HIOL against HepG2 cell lines has not been explored till date. Hence, we scrutinize the effect of HIOL against HepG2 cell lines through using the MTT assay. The results are shown in Fig. 1.

\section{RESULTS}

In the present study, intraperitoneal injection of single dose of DEN $(200 \mathrm{mg} / \mathrm{kg} \mathrm{bw})$ induced severe biochemical changes as well as oxidative damage in hepatic tissue. There was a significant rise in the levels of diagnostic marker enzymes (aspartate aminotransferase [AST], alanine tranaminase [ALT], and ALP) in the serum of (Group 2) DENtreated animals when compared to control group. The administration of HIOL to the Groups 5 and 6 restored the levels of these enzymes near to the normalcy when compared to the negative control Group 2 rats. In Group 3 HIOL alone administered rats versus control, no significant changes were observed. Group 4 with a low dose of HIOL elevated the minimal effect while compared to the normal. The reduction in the liver enzyme levels in HIOL-treated groups depicts the impact of DEN-treated animals. The activities of these enzymes in liver tissue were reversed to near normal levels in HIOL treated rats. This may be due to the protective effect of HIOL against tissue damage and OS induced by DEN administration in rats. Administration of DEN induced a significant increase in the level of LPO measured in terms of MDA which was collateralized by significant reduction in the level of GSH in the liver tissue of DEN-treated animals as compared to normal. GSH plays an important role in the regulation of a variety of cell functions and in cell protection from oxidative injury. Depletion of GSH results in enhanced lipid peroxidation can cause increased GSH as observed in the present study. The treatment with HIOL significantly counteracted the DEN-induced lipid peroxidation and restored the level of GSH to near normal level in Groups 5 and 6 rats as compared to that of DENinduced animals. However, HIOL treated with minimal dose Group 4 does not show any significant compared with DEN-administered rats. Moreover, HIOL alone treated Group 3 animals remain as control. The activities of antioxidant enzymes GPx, GR, SOD, and CAT were significantly lower in liver tissue of DEN injected rats as compared than the normal rats. The observed reduction in the activities of GPx and GR 
in DEN induced oxidative damage due to decreased availability of the substrate reduced GSH. The treatment with HIOL significantly reversed all these DEN alteration in the activity of antioxidant enzymes (SOD, CAT, GPx, and GR) in Groups 5 and 6 rats to near normal status. The HIOL alone treated Group 3 rats did not show any significant change when compared with control rats which indicating that HIOL does not produce any toxic or adverse effects. The slight changes occur in rats treated with a minimal dose of HIOL Group 4 when compared with DEN-treated rats. The results are shown in Tables 1 and 2 .

\section{Histopathological examination}

The histology of the liver tissue was examined under the microscope. The liver from the control (Group 1) showed the normal architecture and cytoplasm of hepatic cells, displayed a small uniform nuclei and nucleoli and granulated cytoplasm as well as a central vein. The liver tissue from rats treated with HIOL alone (Group 3) displayed no significant differences compared with those of the rats in the control but minor sinusoidal congestion exhibited. Compared with Group 3, the liver tissues from rats treated with a minimal dose of HIOL (Group 4) also had a normal lobular organization, represented by a central vein, hepatic cords, and sinusoids, but displayed moderate-to-severe sinusoidal and venous congestions. DEN treatment alone (Group 2) resulted in the loss of the normal architecture, with the tissues displaying instead a granular cytoplasm with large hyperchromatic nuclei and displayed an anaplastic activity with inflammatory cell infiltration and fibroblastic cell proliferation, dividing the cancer and the necrosed hepatocytes of the parenchyma into nodules. Although the DEN with HIOL-treated group (Groups 5 and 6 ) reversed near to the normal level compared with control rats. The results are shown in Fig. 2.

\section{DISCUSSION}

Hepatocarcinogenesis displays a serious health issue after lung cancer. Much endeavor was made for the treatment of liver cancer. Hence, the updated treatments were used for hepatocellular carcinoma (HCC) such as surgery, chemotherapy, hormonal therapy, and radiation which produce diverse side effects. Considering all these aspects, the present study was the driving force to find the new alternate molecule or derivatives or analogs with minimal side effects which is made the heed to sieve the anticancer agents or drugs from plant products that fulfill the benchmark. Many of the research works were carried out by the researchers all over world to assess the potent therapeutic compound from medicinal plants for various diseases including tumor. Cancer is the one of the complicated diseases receiving the great interest to resolve in present scenario $[25,26]$

It has been suggested from our previous reports that OS through interaction with sulfhydryl (-SH) group of GSH results in an increased level of lipid peroxidation. Increasing the ROS production shows mutations of tumor suppressors and damaging the side chain fatty acid in lipid molecule in the cell membrane as well as induces carcinogenesis, and thereby leads to lipid peroxidation [27]. Lipid peroxidation plays a significant role in the process of DEN-induced carcinogenesis and can lead to the production of several toxic products, such as MDA and 4-hydroxynonenal which can hamper the antioxidant defense mechanism and carcinogenicity. [28]. In the present study, administration of DEN revealed a pronounced increase in lipid peroxidation rate represented in the elevated level of MDA and depletion of GSH level. The GSH is an important endogenous antioxidant responsible for free radical scavenging OS condition several carcinogenesis. The depletion GSH content after DEN administration results in the breakdown of the redox balance, thereby affecting the HIOL status and augment the peroxidation process. It has been well documented that HIOL showed potential scavenger of hydroxyl radicals and hydrogen peroxide [8]. In this study we proved that HIOL-treated rats demonstrated that enhanced levels of $-\mathrm{SH}$ groups. This may imply that HIOL prevents the oxidation of free or protein-bound HIOL and thus confers potent antioxidant against DENinduced carcinogenesis.
Glutathione-S-transferase (GST) plays an important role in regulating MAPK pathway involved in the cellular response, apoptosis, proliferation, cellular survival as well as death signals through protein:protein interactions and also key role to detoxify the electrophiles produced by ROS through electrophile conjugation with GSH [29]. Further, it has been well documented that excessive oxidation due to administration of DEN may affect cellular events through decreased level of GST [30]. HIOL supplementation and it leads to decrease the production of toxic free radicals by augmenting the levels of GST.
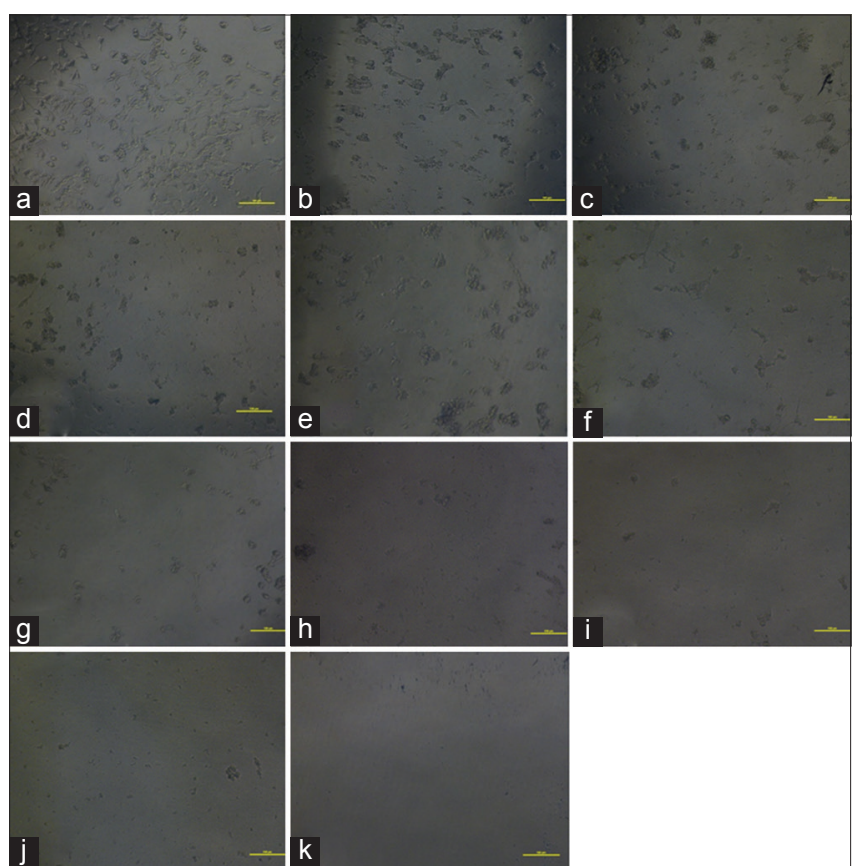

Fig. 1: Cytotoxicity - MTT assay on HepG2 cells - (a) control cells (b) Hinokitiol (HIOL) $1 \mu \mathrm{g} / \mathrm{ml}$ (c) HIOL $2 \mu \mathrm{g} / \mathrm{ml}$ (d) HIOL $3 \mu \mathrm{g} / \mathrm{ml}$ (e) HIOL $4 \mu \mathrm{g} / \mathrm{ml}$ (F) HIOL $5 \mu \mathrm{g} / \mathrm{ml}$ (g) HIOL $6 \mu \mathrm{g} / \mathrm{ml}$ (h) HIOL $7 \mu \mathrm{g} / \mathrm{ml}$ (i) HIOL $8 \mu \mathrm{g} / \mathrm{ml}$ (j) HIOL $9 \mu \mathrm{g} / \mathrm{ml}$ (k) HIOL $10 \mu \mathrm{g} / \mathrm{ml}$

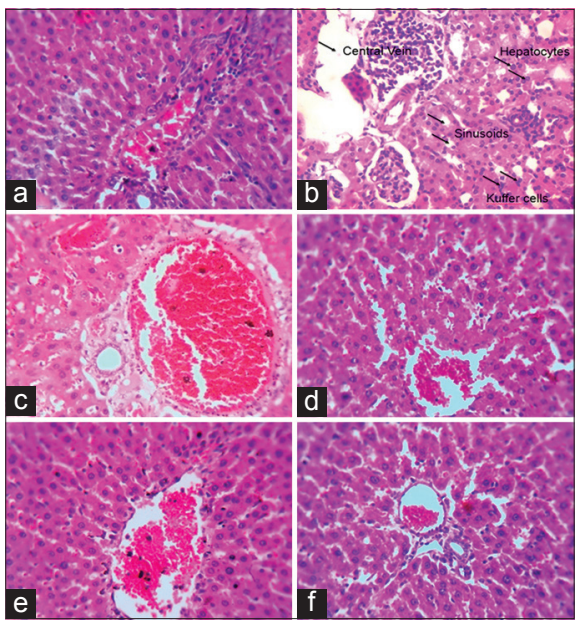

Fig. 2: The plates of histopathological evaluation of rat

liver in experimental animal. (a) Control - normal saline,

(b) diethylnitrosamine (DEN)- $200 \mathrm{mg} / \mathrm{kg} / \mathrm{body}$ weight (bw) (section shows structure of liver presented hepatic congestion at sinusoids and the portal vessel, peri center globular microsteatosis, Kuffer cell proliferation, hepatocyte diffuse necrosis, and mononuclear infiltrate), (c) DEN $(200 \mathrm{mg} / \mathrm{kg} / \mathrm{bw})$ + Hinokitiol (HIOL) (25 $\mu \mathrm{g} / \mathrm{ml})$, (d) HIOL alone $75 \mu \mathrm{g} / \mathrm{ml},(e)$ DEN $(200 \mathrm{mg} / \mathrm{kg} / \mathrm{bw})+$ HIOL $(50 \mu \mathrm{g} / \mathrm{ml})$, (f) DEN (200 mg/kg/bw)+ HIOL $(75 \mu \mathrm{g} / \mathrm{ml})$ 
Table 1: The effect of HIOL in DEN-induced rats on liver enzymes

\begin{tabular}{|c|c|c|c|c|c|c|}
\hline Groups & Normal & $\begin{array}{l}\text { DEN alone } \\
(200 \mathrm{mg} / \mathrm{kg} / \mathrm{bw})\end{array}$ & $\begin{array}{l}\text { HIOL alone } \\
(75 \mu \mathrm{g} / \mathrm{ml})\end{array}$ & $\begin{array}{l}\text { DEN+HIOL } \\
(200 \mathrm{mg} / \mathrm{kg} / \mathrm{bw}) \\
+(25 \mu \mathrm{g} / \mathrm{ml})\end{array}$ & $\begin{array}{l}\text { DEN+HIOL } \\
(200 \mathrm{mg} / \mathrm{kg} / \mathrm{bw}) \\
+(50 \mu \mathrm{g} / \mathrm{ml})\end{array}$ & $\begin{array}{l}\text { DEN+HIOL } \\
(200 \mathrm{mg} / \mathrm{kg} / \mathrm{bw})+(75 \mu \mathrm{g} / \mathrm{ml})\end{array}$ \\
\hline ALT & $36.22 \pm 2.32$ & $115.23 \pm 3.22 * a$ & $37.11 \pm 1.62 \mathrm{NS}$ & $75.65 \pm 2.42 * b$ & $62.83 \pm 3.32 * b$ & $58.33 \pm 2.42 * \mathrm{~b}$ \\
\hline AST & $107.75 \pm 2.42$ & $402.34 \pm 2.11 * a$ & 109.21 \pm 3.48 NS & $255.21 \pm 2.35 * \mathrm{~b}$ & $122.54 \pm 2.51 * \mathrm{~b}$ & $112.32 \pm 1.12 * b$ \\
\hline ALP & $48.22 \pm 2.62$ & $121.15 \pm 1.78 * a$ & $50.32 \pm 1.44 \mathrm{NS}$ & $85.25 \pm 2.32 * \mathrm{~b}$ & $55.65 \pm 3.22 * \mathrm{~b}$ & $51.42 \pm 2.32 * \mathrm{~b}$ \\
\hline
\end{tabular}

Results are expressed as Mean \pm SD for 6 rats. Comparisons are made between: (a) Normal and DEN alone; (b) DEN alone and HIOL Treated. NS - Normal and HIOL alone. *Statistically significant ( $<<0.05$ ), NS: Non-significant. SD: Standard deviation, HIOL: Hinokitiol, DEN: Diethylnitrosamine, ALT: Alanine tranaminase, AST: Aspartate aminotransferase, ALP: Alkaline phosphatase, bw: Body weight

Table 2: The effect of HIOL in DEN-induced rats on enzymatic anti oxidants

\begin{tabular}{|c|c|c|c|c|c|c|}
\hline Groups & Normal & $\begin{array}{l}\text { DEN alone } \\
(200 \mathrm{mg} / \mathrm{kg} / \mathrm{bw})\end{array}$ & $\begin{array}{l}\text { HIOL alone } \\
(75 \mu \mathrm{g} / \mathrm{ml})\end{array}$ & $\begin{array}{l}\text { DEN+HIOL } \\
(200 \mathrm{mg} / \mathrm{kg} / \mathrm{bw}) \\
+(25 \mu \mathrm{g} / \mathrm{ml})\end{array}$ & $\begin{array}{l}\text { DEN+HIOL } \\
(200 \mathrm{mg} / \mathrm{kg} / \mathrm{bw}) \\
+(50 \mu \mathrm{g} / \mathrm{ml})\end{array}$ & $\begin{array}{l}\text { DEN+HIOL } \\
(200 \mathrm{mg} / \mathrm{kg} / \mathrm{bw})+(75 \mu \mathrm{g} / \mathrm{ml})\end{array}$ \\
\hline LPO & $1.83 \pm 0.08$ & $42.11 \pm 0.22 * a$ & $2.11 \pm 0.11 \mathrm{NS}$ & $8.32 \pm 0.23 * b$ & $3.21 \pm 0.42 * b$ & $3.83 \pm 0.84 * b$ \\
\hline GPx & $116.85 \pm 2.28$ & $32.65 \pm 2.41 * a$ & $117.25 \pm 1.12 \mathrm{NS}$ & $65.25 \pm 2.85 * b$ & $112.24 \pm 2.11^{*} \mathrm{~b}$ & $115.52 \pm 3.41 * b$ \\
\hline GR & $192.55 \pm 2.23$ & $24.25 \pm 4.32 * a$ & $192.44 \pm 3.45 \mathrm{NS}$ & $104.71 \pm 3.52 * b$ & $185.32 \pm 2.41^{*} \mathrm{~b}$ & $190.25 \pm 3.51 * b$ \\
\hline SOD & $7.93 \pm 0.69$ & $2.33 \pm 0.22 * a$ & $7.32 \pm 0.44 \mathrm{NS}$ & $4.41 \pm 0.25 * b$ & $7.35 \pm 0.25 * b$ & $7.42 \pm 0.21 * b$ \\
\hline CAT & $69.34 \pm 2.65$ & $22.65 \pm 1.22 * a$ & $69.54 \pm 3.36 \mathrm{NS}$ & $42.75 \pm 2.52 * b$ & $66.78 \pm 2.33^{*} \mathrm{~b}$ & $68.55 \pm 2.45^{*} \mathrm{~b}$ \\
\hline
\end{tabular}

Results are expressed as Mean \pm SD for 6 rats. Comparisons are made between: (a) Normal and DEN alone; (b) DEN alone and HIOL treated. NS - Normal and HIOL alone. *Statistically significant ( $\mathrm{p}<0.05$ ), NS: Non-significant, SOD: Superoxide dismutase, CAT: Catalase, GPx: Glutathione peroxidase, GSH: Glutathione, LPO: Lipid peroxidation, GR: Glutathione reductase. SD: Standard deviation, bw: Body weight, HIOL: Hinokitiol, DEN: Diethylnitrosamine

Glycation and OS are closely linked and are often referred to as "glycoxidation" process which is believed to be involved in the complications associated with several disorders including diabetes, cardiovascular disease, and Alzheimer's disease, in addition to various forms of cancer. The activities of CAT and GPx are significantly decreased by superoxide radical and by glycation reactions. The GSH peroxidase along with GSH catalyzed the reduction of hydrogen peroxide into nontoxic metabolites [31].

The DEN-induced OS is responsible for the loss of antioxidant enzymes such as SOD, CAT, GPX, and GR activities significantly. The divulge inability of the enzymatic antioxidants to detoxify intracellular ROS to protect the cellular structures against oxidative distress which is responsible for dismutation from superoxide radicals to $\mathrm{H}_{2} \mathrm{O}_{2}$ and detoxify the $\mathrm{H}_{2} \mathrm{O}_{2}$ into water, respectively; therefore, it will protect against the tissue damage [32]. As per previous results, oral administration of HIOL was absorbed biologically in hepatocytes of rats and they excite the recovery of the antioxidant enzymes. Except this, free radical scavenging effects are capable of upregulating the antioxidant enzyme synthesis [33]. We can conclude through its antioxidant activity, preventing the antioxidant defense and the covalent binding of reactive intermediates which results in the reduction of diethyl nitrosamine-induced hepatocarcinogenesis as evident in the histological and biochemical results.

In our study, DEN decreased the activities of SOD and CAT enzymes in rats. The inhibition of SOD activity in hepatitis rats may be attributed to inefficient scavenging of ROS, which might be implicated to oxidative inactivation of SOD. CAT is one of the heme proteins, which decomposes the hydrogen peroxide leads to protect the tissues from highly reactive hydroxyl radicals [34]. Our findings are supported by the previous studies, decline of SOD and CAT activity in DEN-induced hepatitis rats. However, pretreatment of HIOL remarkably increased the SOD and CAT activity in DEN-induced hepatitis, and it was indicated that HIOL significantly prevents the superoxide anions and hydrogen peroxide radicals by SOD and CAT in DEN-intoxicated rats.

In our study, we observed the depleted activities of GR and GPx in hepatitis rats. DEN decreased the GPx and GR activities due to the free radicals, which led to interaction with these proteins and modulation of their action. GPx reduced the $\mathrm{H}_{2} \mathrm{O}_{2}$ to water in the presence of GSH and GR reduces the oxidized GSH into reduced GSH, which is essential for defense against free radicals. Glutathione peroxidase is efficient
ROS scavengers with high affinity for $\mathrm{H}_{2} \mathrm{O}_{2}$. They can reduce the $\mathrm{H}_{2} \mathrm{O}_{2}$ and organic hydroperoxides, thereby protecting cells from oxidative damage. GPXs were widely distributed in plant cells with highly conservative cysteine residue [35].

One of the sensitive indices in liver cell injury is decline of SOD enzyme activity. SOD is one of the enzymes in enzymatic antioxidant defense system. It declines the toxic effect produced by superoxide anion by conversion of hydrogen peroxide. HIOL causes a significant elevation in liver SOD activity and thus lessen free radical-induced oxidative injury to the liver. CAT is an antioxidant enzyme which is commonly present in all animal tissues, and the highest activity is found in liver and red blood cells. CAT defends the tissues from highly reactive hydroxyl radicals by decomposing hydrogen peroxide. Therefore, decline in the CAT activity may cause various harmful effects due to hydrogen peroxide and superoxide radical assimilation [36]. The HIOL increases the CAT activity level. Restoration of CAT activity and thereby the decrease of hepatic damage might reflect the antioxidant activity of HIOL used in this experiment.

GSH, a non-enzymatic antioxidant is one of the most plentiful tripeptide found in the liver. It gets rid of the ROS for instance superoxide radicals and hydrogen peroxide and preserves protein HIOLs of membrane. HIOL administration significantly restored the level of GSH [37].

ALT, AST, and ALP are more important liver marker enzymes. ALT catalyzes the transfer of amino group from $\mathrm{L}$-alanine to $\alpha$-ketoglutarate. ALT levels are increased in the DEN-induced rats due to reversible transamination reaction being L-glutamate and pyruvate. It indicates the liver damage in DEN-induced rats, and after administration of HIOL, the ALT levels are retrieved. ALP is an enzyme that transports metabolites across cell membrane and increases the level due to tissue damage and OS. This enzyme turned back to their normal serum levels after treatment with HIOL perhaps due to the prohibition of intracellular enzyme permeation created by cell membrane stability or cellular regeneration in DEN-induced rats. AST is present in both mitochondria and cytoplasm. AST levels are increased when treated with DEN, and it was reversed due to administration of HIOL when compared with DEN induces rats [38].

Alpha-fetoprotein is a fetal-specific glycoprotein secreted from fetal liver and yolk sac, rapidly falls few weeks after birth. Attack-free 
period (AFP) is the most important serum marker to predict liver cancer occurrence. The serum AFP level not only to diagnose but also prediction for the prognosis of HCC. As a relatively cheap and mature method, AFP is the most important serum marker for diagnosis of HCC. In the same line of our results reported that AFP serum level had been elevated in DEN-induced rats and HIOL treatment has an ameliorative effect on AFP $[39,40]$.

The histopathological analysis of liver confirmed the observed modification of serum enzymatic levels to liver injury and their attributes on health. The normal hepatic tissue in our study demonstrated the usual architecture with a central vein and hepatocytes radiating from it. The portal triad consisted of hepatic artery, portal vein, and bile duct which constituted various zones surrounding these areas. DEN produced centrizonal necrosis, hydropic, and fatty changes with sinusoids congestion $[41,42]$. After treatment with HIOL, repaired the liver architecture and protected the hepatic tissue from degenerative and fatty alterations, by averting the toxic chemical reaction, OS, lipid peroxidation, molecular changes in the liver tissues, and micro- and macro-vesicular fatty changes ultimately leading to necrosis.

\section{CONCLUSION}

Data from these study state that HIOL shown the potent antioxidant effect against DEN-induced hepatoperturbations in rats. The potent effect of Hinokitiol due to their anti-oxidant potential against in DEN induced rats by preventing the enzymes. HIOL possesses chemopreventive action through antioxidant property and reduces the biochemical markers which are upregulated in hepatocarcinogenesis. This will start new prospects that HIOL may used for the treatment of liver cancer. Furthermore, extensive scrutinization of HIOL is required to screen the pharmacological applicability in the treatment of hepatocarcinogenesis.

\section{REFERENCES}

1. Siddique AI, Mani V, Arivalagan S, Thomas NS, Namasivayam N. Asiatic acid attenuates pre-neoplastic lesions, oxidative stress, biotransforming enzymes and histopathological alterations in 1,2-dimethylhydrazine-induced experimental rat colon carcinogenesis. Toxicol Mech Methods 2017;27:136-50.

2. Shanmugarajan TS, Arunsundar M, Somasundaram I, Krishnakumar E, Sivaraman S, Ravichandiran V. Cardio protective effect of Ficus hispida Linn on cyclophosphamide provoked oxidative myocardial injury in a rat model. Int J Pharmacol 2008;1:1-10.

3. Friedberg EC, Meira LB. Database of mouse strains carrying targeted mutations in genes affecting biological responses to DNA damage version 7. DNA Repair (Amst) 2006;5:189-209.

4. Shaked H, Hofseth LJ, Chumanevich A, Chumanevich AA, Wang J, Wang Y, et al. Chronic epithelial NF-kB activation accelerates APC loss and intestinal tumor initiation through iNOS up-regulation. Proc Natl Acad Sci U S A 2012;109:14007-12.

5. Afzal M, Kazmi I, Khan R, Rana P, Kumar V, Al-Abbasi FA, et al. Thiamine potentiates chemoprotective effects of ibuprofen in DEN induced hepatic cancer via alteration of oxidative stress and inflammatory mechanism. Arch Biochem Biophys 2017;623624:58- 63 .

6. Velu P, Vijayalakshmi A, Iyappan P, Indumathi D. Evaluation of antioxidant and stabilizing lipid peroxidation nature of solanum xanthocarpum leaves in experimentally diethylnitrosamine induced hepatocellular carcinogenesis. Biomed Pharmacother 2016;84:430-7.

7. Zhou F, Shen T, Duan T, Xu YY, Khor SC, Li J, et al. Antioxidant effects of lipophilic tea polyphenols on diethylnitrosamine/phenobarbitalinduced hepatocarcinogenesis in rats. In Vivo 2014;28:495-503.

8. Huang CH, Jayakumar T, Chang CC, Fong TH, Lu SH, Thomas PA, et al. Hinokitiol exerts anticancer activity through downregulation of MMPs 9/2 and enhancement of catalase and SOD enzymes: In vivo augmentation of lung histoarchitecture. Molecules 2015;20:17720-34.

9. Ye J, Xu YF, Lou LX, Jin K, Miao Q, Ye X, et al. Anti-inflammatory effects of hinokitiol on human corneal epithelial cells: An in vitro study. Eye (Lond) 2015;29:964-71.

10. Li LH, Wu P, Lee JY, Li PR, Hsieh WY, Ho CC, et al. Hinokitiol induces DNA damage and autophagy followed by cell cycle arrest and senescence in gefitinib-resistant lung adenocarcinoma cells. PLoS One 2014;9:e104203.

11. King J. The dehydrogenases or oxidoreductases-Lactate dehydrogenase. In: King J, editor. Practical Clinical Enzymology. London: Van Nostrand Company Ltd.; 1965. p. 83-93.

12. King J. The hydrolases-acid and alkaline phosphatases. In: King J, editor. Practical Clinical Enzymology. London: Van Nostrand Company Ltd.; 1965. p. 191-208.

13. King J. The transferases-alanine and aspartate transaminases. In: King J, editor. Practical Clinical Enzymology. London: Van Nostrand Company Ltd.; 1965. p. 121-38.

14. Premalatha B, Sachdanandam P. Effect of Semecarpus anacardium nut milk extract on rat serum alpha-fetoprotein level in aflatoxin B mediated hepatocellular carcinoma. Fitoterapia 1999;70:279-83.

15. Ohkawa H, Ohishi N, Yagi K. Assay for lipid peroxides in animal tissues by thiobarbituric acid reaction. Anal Biochem 1979;95:351-8.

16. Misra HP, Fridovich I. The role of superoxide anion in the autoxidation of epinephrine and a simple assay for superoxide dismutase. J Biol Chem 1972;247:3170-5

17. Sinha AK. Colorimetric assay of catalase. Anal Biochem 1972;47:389-94.

18. Ahrens RA. Glutathione peroxidase: A role for selenium (Rotruck 1972). J Nutr 1997;127:1052S-1053S.

19. Habig WH, Pabst MJ, Jakoby WB. Glutathione S-transferases. The first enzymatic step in mercapturic acid formation. J Biol Chem 1974;249:7130-9.

20. Ellman GL. Tissue sulfhydryl groups. Arch Biochem Biophys $1959 ; 82: 70-7$

21. Staal GE, Visser J, Veeger C. Purification and properties of glutathione reductase of human erythrocytes. Biochim Biophys Acta 1969;185:39- 48

22. Raja S, Ravindranadh K. In vivo antioxidant activity of Limnophila heterophylla and Michelia champaca. Int J Pharm Pharm Sci $2017 ; 9: 241-6$

23. Fatima Z, Abderrahmane B, Seddik K, Lekhmici A. Antioxidant activity assessment of Tamus communis L. roots. Int J Pharm Pharm Sci 2016;8:64-71

24. Banu S, Kumar G, Murugesan AG. Ethanolic leaves extract of Trianthema portulacastrum $\mathrm{L}$. ameliorates aflatoxin B1 induced hepatic damage in rats. Indian J Clin Biochem 2009;24:250-6.

25. Santos NP, Colaço AA, Oliveira PA. Animal models as a tool in hepatocellular carcinoma research: A review. Tumour Biol 2017;39:1010428317695923

26. Pang RW, Joh JW, Johnson PJ, Monden M, Pawlik TM, Poon RT. Biology of hepatocellular carcinoma. Ann Surg Oncol 2008;15:962-71.

27. Shanmugarajan TS, Prithwish N, Somasundaram I, Arunsundar M, Niladri M, Lavande JP, et al. Mitigation of azathioprine-induced oxidative hepatic injury by the flavonoid Quercetin in wistar rats. Toxicol Mech Methods 2008;18:653-60.

28. Kim NH, Heo JD, Kim TB, Rho JR, Yang MH, Jeong EJ. Protective effects of ethyl acetate soluble fraction of Limonium tetragonum on diethylnitrosamine-induced Liver fibrosis in rats. Biol Pharm Bull 2016;39:1022-8

29. Arunsundar M, Shanmugarajan TS, Ravichandran V. 3,4 di hydroxyl phenyl ethanol attenuates spatio-cognitive deficits in an alzheimer's disease mouse model: Modulation of the molecular signals in neuronal survival-apoptotic programs. Neurotox Res 2015;27:143-55.

30. Sadek KM, Abouzed TK, Abouelkhair R, Nasr S. The chemoprophylactic efficacy of an ethanol Moringa oleifera leaf extract against hepatocellular carcinoma in rats. Pharm Biol 2017;55:1458-66.

31. Arunsundar M, Shanmugarajan TS. Ficus hispida modulates oxidativeinflammatory damage in a murine model of diabetic encephalopathy. Ann Biol Res 2010;1:90-7.

32. Pradeep K, Mohan CV, Gobianand K, Karthikeyan S. Silymarin modulates the oxidant-antioxidant imbalance during diethylnitrosamine induced oxidative stress in rats. Eur J Pharmacol 2007;560:110-6.

33. Nakagawa Y, Tayama K. Mechanism of mitochondrial dysfunction and cytotoxicity induced by tropolones in isolated rat hepatocytes. Chem Biol Interact 1998;116:45-60.

34. Shanmugarajan TS, Niladri M, Somasundaram I, Prithwish N, Patel S, Ahamed KF. Antioxidant potential of Gaultheria fragrantissima against adjuvant induced arthritis in wistar rats. Pharm Biol 2009; 47:414-21

35. Zhao Y, Liu Y, Lan X, Xu G, Sun Y, Li F, et al. Effect of Dendrobium officinale extraction on gastric carcinogenesis in rats. Evid Based Complementary Altern Med 2016. Article ID: 1213090, 8 Pages.

36. Wheeler MD, Kono H, Yin M, Rusyn I, Froh M, Connor HD, et al. Delivery of the $\mathrm{Cu} / \mathrm{Zn}$-superoxide dismutase gene with adenovirus reduces early alcohol-induced liver injury in rats. Gastroenterology.2001; 
120(5):1241-1250

37. Yuan L, Kaplowitz N. Glutathione in liver diseases and hepatotoxicity. Mol Aspects Med 2009;30:29-41

38. Li S, Tan H, Wang N, Zhang Z, Lao L, Wong C, et al. The role of oxidative stress and antioxidants in liver diseases. Int J Mol Sci 2015; 16:26087-124.

39. He G, Yu G, Temkin V, Ogata H, Kuntzen C, Sakurai T, et al. Hepatocyte $\mathrm{IKKb} / \mathrm{NF}-\mathrm{kB}$ inhibits tumor promotion and progression by preventing oxidative stress-driven STAT3 activation. Cancer Cell 2010;17:286-97.
40. Li D, Mallory T, Satomura S. AFP-L3: A new generation of tumor marker for hepatocellular carcinoma. Clin Chim Acta 2001;313:15-9.

41. Kadasa NM, Abdallah H, Afifi M, Gowayed S. Hepatoprotective effects of curcumin against diethyl nitrosamine induced hepatotoxicity in albino rats. Asian Pac J Cancer Prev 2015;16:103-8.

42. Sakurai T, He G, Matsuzawa A, Yu GY, Maeda S, Hardiman G, et al. Hepatocyte necrosis induced by oxidative stress and IL-1 alpha release mediate carcinogen-induced compensatory proliferation and liver tumorigenesis. Cancer Cell 2008;14:156-65. 